\title{
Neuroprotective role of Tinospora cordifolia extract in streptozotocin induced neuropathic pain
}

\author{
Jorige Archana ${ }^{\oplus 1^{*}}$, Akula Annapurna², Panuganti Devayani ${ }^{3}$ \\ ${ }^{1 *} R B V R R$ Women's College of Pharmacy (Affiliated to Osmania University), Barktpura, \\ Hyderabad-500039, Telangana, India, ${ }^{2}$ University College of Pharmaceutical Sciences, Andhra \\ University, Visakhapatnam-530003, Andhra pradesh, India, ${ }^{3}$ CSIR-IICT, Hyderabad-500007
}

\begin{abstract}
Diabetic Neuropathy (DN) is one of the prevailing micro vascular complications of diabetes which can be characterized by neuropathic pain. Streptozotocin (STZ) induced diabetes in the rat has been increasingly used as a model of painful diabetic neuropathy. STZ injection leads to neurotoxicity of peripheral nerves that leads to development of Peripheral Diabetic Neuropathy in rat model. The present study was aimed at exploring the protective role of Tinospora cordifolia extract in STZ induced neurotoxicity and evaluating mechanisms responsible for attenuating neuropathic pain. Neuropathic pain markers like hyperalgesia, allodynia and motor deficits were assessed before STZ injection and after the treatment with $250 \mathrm{mg} / \mathrm{kg}$ and $500 \mathrm{mg} / \mathrm{kg}$ dose of Tinospora cordifolia. Oxidative stress markers, NGF expression in sciatic nerve were observed after seven weeks treatment. Our results demonstrated that seven weeks treatment with Tinospora cordifolia leaf extract significantly relieved thermal hyperalgesia and allodynia by increasing the antioxidant enzyme levels, decreasing the lipid peroxidation and by increasing the Nerve growth factor (NGF) expression in diabetic rat sciatic nerves. Our findings highlighted the beneficial effects of oral administration of Tinospora cordifolia extract in attenuating diabetic neuropathic pain, possibly through a strong antioxidant activity and by inducing NGF m RNA in sciatic nerves.
\end{abstract}

Keywords: Oxidative Stress. Hyperalgesia. Allodynia. Sciatic nerves. Nerve growth factor (NGF).

\section{INTRODUCTION}

Diabetic Neuropathy (DN) is a nerve damaging disorder that is associated with Diabetes mellitus. As reported by the latest International Diabetes Federation (IDF) publication, the incidence and prevalence of diabetes is proliferating at an alarming rate in both developed and developing countries, particularly in India and China. The reported prevalence of diabetic peripheral neuropathy ranges from $16 \%$ to as high as $66 \%$. Amputation in people with diabetes is 10 to 20 times more common compared to those of non-diabetic people. Peripheral neuropathy is the most common

*Correspondence: J. Archana. RBVRR Women's College of Pharmacy. Barkatpura, Hyderabad -50039. Telangana, India. Email id: archana_jarc@ yahoo.com form of diabetic neuropathy, affecting the outer nerves of the limbs, particularly those of the feet. It mainly alters sensory function, causing abnormal feelings and progressive numbness which facilitates the development of ulcers (IDF, 2017)

Excess free radical production and ultimate oxidative stress results from provoked glucose metabolic pathways in Diabetes. DN develops on a background of hyperglycemia and an entangled metabolic imbalance, mainly oxidative stress (Hosseini, Abdollahi, 2013). Streptozocin (STZ) induced diabetic rat is the often selected animal model for studying the mechanisms of painful DN and evaluating the potential remedies. The therapies available for DN now a day are limited and weak because of their partial efficacy and side effects (Pabreja et al., 2011). Plantderived antioxidant nutraceuticals can modulate oxidative stress related degenerative diseases by scavenging the free 
radicals (Thatte et al., 2000). Tinospora cordifolia (TC) is considered as a divine Indian herb in Ayurveda. Recently, the plant is of great interest to researchers across the globe because of its reported medicinal properties. It has proven antioxidant activity in-vitro and in-vivo in maltose fed rat model (Praveen et al., 2012; Sengupta et al., 2009). Tinospora cordifolia is widely used in Ayurveda for treatment of several diseases and used as general tonic, antispasmodic, anti-inflammatory, anti-arthritic, antiallergic and anti-diabetic. The pharmaceutical significance of this plant is mainly because of the leaves, barks and roots which contain various bioactive compounds such as alkaloids, glycosides, lactones, steroids, polysaccharides and aliphatic compounds of medicinal importance. The bitter principles present in the leaves, stems, roots and barks viz. Tinosporine, Tinosporide, Tinosporaside, Cordifolide, Cordifol, Berberine, Cordifolioside A, B, C, Aamritosides $\mathrm{A}, \mathrm{B}, \mathrm{C}$, and Columbin which act as therapeutic agents and play vital role in many therapeutic applications (Pandey et al., 2012). It's role in preventing diabetic neuropathic pain has not been demonstrated till now. Hence in the present study the Ethanolic extract of Tinospora cordifolia (TC) has been evaluated for neuroprotective action and it's possible mode of action in STZ induced neuropathic pain.

\section{MATERIAL AND METHODS}

\section{Animals}

Male Albino Wistar rats aged 3-4 months, weighing about 180-220 g were employed in the study and were procured from Albino Research and Training Institute, Hyderabad. They were fed on a standard chow diet and water ad libitum. All rats were housed at a temperature of $25^{\circ} \mathrm{C}$ under a $12 \mathrm{hr}$ dark/light cycle. All the animal experiments were carried out as per the guidelines of the Committee for the Purpose of Control and Supervision of Experiments on Animals, Ministry of Environment and Forest, Government of India. The experimental protocol has been approved by the IAEC Reg. No 516/ CPCSEA.

\section{Plant material}

Tinospora cordifolia (Thunb.) Miers, commonly known as heart leaf moonseed (English) is a wellknown medicinal herb in Ayurveda. The leaves of Tinospora cordifolia were collected from its natural habitat in Thirupathi, AP, and India. The plant material was identified and authenticated by Dr. K. M. Chetty, Assistant professor, Department of Botany, Sri Venkateswara University, AP, India. Tirupati (Voucher specimen No: 2117).

\section{Preparation of Tinospra cordifolia Extract (TCE)}

The leaves of Tinospra cordifolia were washed and dried in the open air under the shade for one week, cut into small pieces and powdered mechanically. The powdered material $(1 \mathrm{~kg})$ was placed in a thimble and extracted with $70 \%$ ethanol in a Soxhlet apparatus for 20-24 h. Solvents were removed at temperature below $50{ }^{\circ} \mathrm{C}$ in an oven. The residue (extract) of respective plant material was stored at $4{ }^{\circ} \mathrm{C}$ until used. The extract (TCE) yield (\% w/w) from the plant material was recorded as $5.4 \%$.

\section{Experimental induction of Type 1 Diabetes Mellitus}

Diabetes was experimentally induced in overnight fasted adult rats by administering a single intravenous dose of $50 \mathrm{mg} / \mathrm{kg}$ streptozotocin (STZ), freshly dissolved in $0.1 \mathrm{~mol} / \mathrm{L}$ citrate buffer ( $\mathrm{pH} 4.5$ ). Control animals received an equal volume of citrate buffer. STZ induced diabetic animals were given $10 \%(\mathrm{w} / \mathrm{v})$ glucose in drinking water for 24 hours to avoid early mortality due to sudden hypoglycemic period that occurs immediately after the lysis of the pancreatic islet cells by STZ. The animals showing plasma glucose levels more than 300 $\mathrm{mg} / \mathrm{dl}$ after $72 \mathrm{~h}$ of STZ injection were considered diabetic and included in the study.

\section{Experimental design}

Animals were randomly separated into four groups having eight animals each. Non Diabetic Control (NDC), Diabetic control (DC), TCE 250 treated (Diabetic + $250 \mathrm{mg} / \mathrm{kg} /$ day Tinospora cordifolia ethanolic extract), TCE 500 treated (Diabetic $+500 \mathrm{mg} / \mathrm{kg}$ /day Tinospora cordifolia ethanolic extract) treated groups. One week after the induction of diabetes test drugs in required doses were suspended in $1 \mathrm{~mL}$ of drinking water and given orally by gastric gavage for seven consecutive weeks at same time on each day.

\section{Blood sampling}

For glucose estimation and biochemical estimations blood was drawn from retro orbital plexus by using a 
micro capillary technique and serum was separated by centrifugation at $3000 \mathrm{rpm}$ for 10 minutes.

\section{Estimation of Blood glucose}

Serum glucose was quantified enzymatically using the glucose oxidase and peroxidase method (Jakobsen, L. Kramer,1960)

\section{Serum lipid profile}

The serum concentration of total cholesterol was determined by enzymatic methods using cholesterol Oxidase - Peroxidase method. Cholesterol is measured enzymatically in serum or plasma in a series of coupled reactions that hydrolyse cholesteryl esters and oxidise the 3-OH group of cholesterol. One of the reaction's by-products, $\mathrm{H}_{2} \mathrm{O}_{2}$ is measured quantitatively in a peroxidase catalyzed reaction that produces a colour. The colour intensity is proportional to cholesterol concentration. The levels of triacylglycerol in the serum were estimated enzymatically by Trinder method after hydrolysis by lipoprotein lipase in glycerol, then to glycerol phosphate and then to dihydroxyacetone phosphate and $\mathrm{H}_{2} \mathrm{O}_{2}$, which in the presence of peroxidase was converted to aminophenazone.

Low and very low density lipoproteins are precipitated by a solution containing PEG 6000, leaving behind the high density lipoproteins in solution. HDL Cholesterol is estimated in the supernatant by a series of enzymatic reactions which are initiated by the oxidation of cholesterol to cholestenone by cholesterol oxidase accompanied by the formation of hydrogen peroxide to form a red colored quinoneimine. Absorbance at $505 \mathrm{~nm}$ is directly proportional to HDL cholesterol concentration.

\section{Behavioral assessment of neuropathic pain}

Neurobehavioral tests for Nociception and motor coordination were performed on each animal before and after the treatment (i.e.before STZ injection and after 8 weeks of STZ injection)(Shaikh, Somani, 2010).

\section{Assessment of Thermal hyperalgesia (Eddy's hot plate method)}

Thermal hyperalgesia was assessed by Eddy's hot plate. The temperature of the hot plate should be maintained at $55{ }^{\circ} \mathrm{C}+1{ }^{\circ} \mathrm{C}$ throughout the experimental period. The latency to first sign of paw licking or jumping response (Index of pain threshold) to avoid thermal pain was taken as an index of pain threshold. (Osikowicz et al., 2008).

\section{Assessment of cold and hot allodynia by tail immersion method}

The tail of each rat was immersed in cold $\left(10^{\circ} \mathrm{C}\right)$ (Courteix et al., 1993) or warm $\left(48^{\circ} \mathrm{C}\right)$ water (Morani et al., 2007) and tail flick latency was recorded until tail withdrawal or signs of struggle were observed.

\section{Assessment of Sensorimotor deficit}

The rats were tested for three times at $25 \mathrm{rpm}$ speed on Rota rod apparatus with an interval of $20 \mathrm{~min}$ between each trial. An average of three readings was taken as the final latency to fall (Szolcsányi et al., 2004).

\section{Biochemical assays}

At the end of the study the animals were killed by decapitation and both the sciatic nerves were immediately isolated carefully and weighed. The sciatic nerve homogenate $(10 \%)$ was prepared with $0.25 \mathrm{M}$ Tris and the homogenate was centrifuged at a temperature of $40{ }^{\circ} \mathrm{C}$ at $4000 \mathrm{rpm}$ for 10 minutes. The pellet was discarded and a portion of the supernatant was again centrifuged at $10000 \mathrm{rpm}$ for 20 minutes to get post mitochondrial supernatant. Various biochemical assays were performed in homogenate and in post mitochondrial fraction (Kamboj et al., 2010). Reduced glutathione (GSH) was determined by Ellman method and the amount of glutathione is expressed as n.mole/mg protein (Ellman, 1959).The assay of superoxide dismutase (SOD) is performed by the method explained by Kakkar et al.. The SOD level was expressed as Units/mg protein (Kakkar et al., 1984). Estimation of catalase was done by observing $\mathrm{H}_{2} \mathrm{O}_{2}$ decomposition by CAT (Catalase). Catalase was expressed as $\mu$ moles of $\mathrm{H}_{2} \mathrm{O}_{2}$ metabolized/ $\mathrm{mg}$ protein /min (Aebi, 1984). The amount of the tissue malondialdehyde (MDA), product of lipidperoxidation formed was measured with thiobarbituric acid at 532 $\mathrm{NM}$. The results were expressed as $\mathrm{n} \mathrm{mol} / \mathrm{mg}$ protein (Ohkawa et al., 1979). The protein content was estimated according to the method of Lowry et al. using albumin as a standard. 


\section{Quantitative Real Time PCR}

Real time PCR was used for quantification of transcripts. Standard curves for each gene were created using three-fold dilution of cDNA obtained from untreated sciatic nerves tissue and were run in triplicate on a 384 well plate. The $\mathrm{Ct}$ values for all the treatments and control for each primer pair were determined simultaneously. All reactions were performed in triplicates in an ABI Prism 7900 HT Real Time PCR System (Applied Biosystems, USA). cDNA prepared from mRNA was amplified using the following primer set (Øvstebø et al., 2003).

$\beta$ - actin :

Forward 5'-CGTTGACATCCGTAAAGACC-3' and Reverse 5-CCACCVVTCCACACAGAGTA-3'

NGF:

Forward 5'- CAGACCGGAACATCACTGTA -3' and Reverse 5' - CCATGGGCCTGGAAGTCTAG-3'

$\Delta C_{t}$ of Test $=\quad$ Test $C_{t}-C_{t}$ of housekeeping gene $\Delta \mathbf{C}_{t}$ of control $=$ Control $C_{t}-C_{t}$ of housekeeping gene $\Delta \Delta \mathbf{C}_{t}=\quad \Delta \mathbf{C}_{t}$ of Test $-\Delta \mathbf{C}_{t}$ of Control

Fold of Expression $=2^{-\Delta \Delta C t}$

\section{Statistical analysis}

All values were expressed as Mean \pm SEM $(n=$ 8/group). Data was analyzed using student's t - test or one way analysis of variance (ANOVA) followed by Tukey-Kramer test for multiple pair wise comparisons between the various treated groups using graph pad prism software. Values with $\mathrm{P}<0.05$ were considered as statistically significant.

\section{RESULTS}

\section{The effect of TCE on Hyperglycemia and serum lipid profile}

All the STZ induced DC rats showed a significant hyperglycemia after 72 hours of STZ administration. After eight week study period the untreated DC rats showed significantly higher blood glucose levels compared to the NDC rats. Seven weeks' treatment with TCE 250 and TCE 500 partially lowered (22.82\% and $24.88 \%$ ) the blood glucose levels of diabetic animals compared to their initial values. However the blood glucose was still above $300 \mathrm{mg} / \mathrm{dl}$ indicating the maintenance of Type 1 Diabetes (Table I).

Both the doses TCE significantly lowered the serum cholesterol as well as the serum triglyceride level in diabetic rats compared to DC rats in a dose dependent manner. There is a significant decrease in HDL cholesterol in diabetic rats when compared to the control group. But TCE treatment had not indicated substantial improvements in HDL cholesterol levels in diabetic rats (Table I).

TABLE I - Effect of Tinospora cordifolia Extract (TCE) on blood glucose and serum lipid profile

\begin{tabular}{|c|c|c|c|c|c|}
\hline \multirow[b]{2}{*}{ Groups } & \multicolumn{2}{|c|}{ Serum blood glucose in $\mathrm{mg} / \mathrm{dl}$} & \multirow{2}{*}{$-\underset{\text { cholesterol in mg/dl }}{\text { Serum }}$} & \multirow{2}{*}{$\begin{array}{c}\text { Serum } \\
\text { triglycerides } \\
\text { mg/dl }\end{array}$} & \multirow{2}{*}{$\begin{array}{c}\text { Serum HDL } \\
\text { cholesterol } \\
\text { mg/dl }\end{array}$} \\
\hline & $\begin{array}{c}72 \text { hrs after STZ } \\
\text { injection }\end{array}$ & $\begin{array}{l}\text { At the end of } \\
\text { the study }\end{array}$ & & & \\
\hline NDC & $104.65 \pm 04.46$ & $106.34 \pm 8.38$ & $73.27 \pm 4.82$ & $99.74 \pm 6.26$ & $36.70 \pm 1.73$ \\
\hline DC & $378.33 \pm 14.92^{*}$ & $406.45 \pm 07.89^{*}$ & $114.55 \pm 7.52^{*}$ & $188.91 \pm 10.25^{*}$ & $20.35 \pm 1.72$ \\
\hline TCE 250 & $415.87 \pm 11.73^{*}$ & $320.95 \pm 17.19$ & $76.87 \pm 6.56^{\#}$ & $125.15 \pm 8.65^{\#}$ & $32.45 \pm 1.89$ \\
\hline
\end{tabular}


TABLE I - Effect of Tinospora cordifolia Extract (TCE) on blood glucose and serum lipid profile

\begin{tabular}{|c|c|c|c|c|c|}
\hline \multirow[b]{2}{*}{ Groups } & \multicolumn{2}{|c|}{ Serum blood glucose in $\mathrm{mg} / \mathrm{dl}$} & \multirow{2}{*}{$-\underset{\text { cholesterol in } \mathrm{mg} / \mathrm{dl}}{\text { Serum }}$} & \multirow{2}{*}{$\begin{array}{c}\text { Serum } \\
\text { triglycerides } \\
\text { mg/dl }\end{array}$} & \multirow{2}{*}{$\begin{array}{c}\text { Serum HDL } \\
\text { cholesterol } \\
\text { mg/dl }\end{array}$} \\
\hline & $\begin{array}{c}72 \text { hrs after STZ } \\
\text { injection }\end{array}$ & $\begin{array}{l}\text { At the end of } \\
\text { the study }\end{array}$ & & & \\
\hline TCE 500 & $405.97 \pm 09.06^{*}$ & $304.97 \pm 14.16^{\#}$ & $70.48 \pm 5.02^{\#}$ & $110.89 \pm 8.35^{\#}$ & $27.83 \pm 1.99$ \\
\hline
\end{tabular}

Values were expressed in Mean \pm SEM ( $n=8 /$ group). ${ }^{*}$ Significantly different from Non diabetic Control $(\mathrm{p}<0.05)$. ${ }^{*}$ Significantly different from Diabetic control group $(\mathrm{p}<0.05)$.

NDC: Non diabetic Control

TCE 250: Group treated with $250 \mathrm{mg}$ Tinospora cordifolia Extract

DC: Diabetic control

TCE500: Group treated with $500 \mathrm{mg}$ Tinospora cordifolia Extract

\section{The effects of TCE on thermal hyperalgesia, allodynia and motor in coordination}

Neuropathy with abnormal sensory perception is the most common complication in Diabetes. In this study, Diabetic rats showed a $41.89 \%$ decrease in basal reaction times after eight weeks of Diabetes. Diabetic rats treated with TCE 250 and TCE 500 for seven weeks restored the reaction times to $95.95 \%$ and $109.46 \%$ of baseline values (Figure 1).

Tail flick latency of DC animals from hot water $\left(48 \pm 10^{\circ} \mathrm{C}\right)$ was significantly less when compared to the normal animals. The tail flick latency reduced to $39.75 \%$ of their baseline values. Seven weeks' treatment with TCE 250 and TCE 500 showed a significant rise in tail flick latency of diabetic rats, indicating the ameliorating effect of Tinospora cordifolia in Diabetic
Neuropathy induced hot allodynia. TCE 250 and TCE 500 treated animals showed $92.21 \%$ and $98.61 \%$ of their basal reaction latencies in tail flick latency (Figure 2).

In cold allodynia test, diabetic rats showed decrease in tail flick latency after eight weeks when compared to control animals and there is a $41.08 \%$ decline of base line tail flick latency. TCE 250 and TCE 500 treatments improved the latencies to $89.03 \%$ and $98.61 \%$ of their baseline values (Figure 3).

There was a significant reduction in the retention time of the diabetic animals on the rotarod due to the development of Neuropathy after eight weeks. After 8 weeks DC rats showed a $70.1 \%$ decline in retention times compared to NDC animals. Both the doses of TC increased the retention times of diabetic animals on rotarod (Figure 4). 


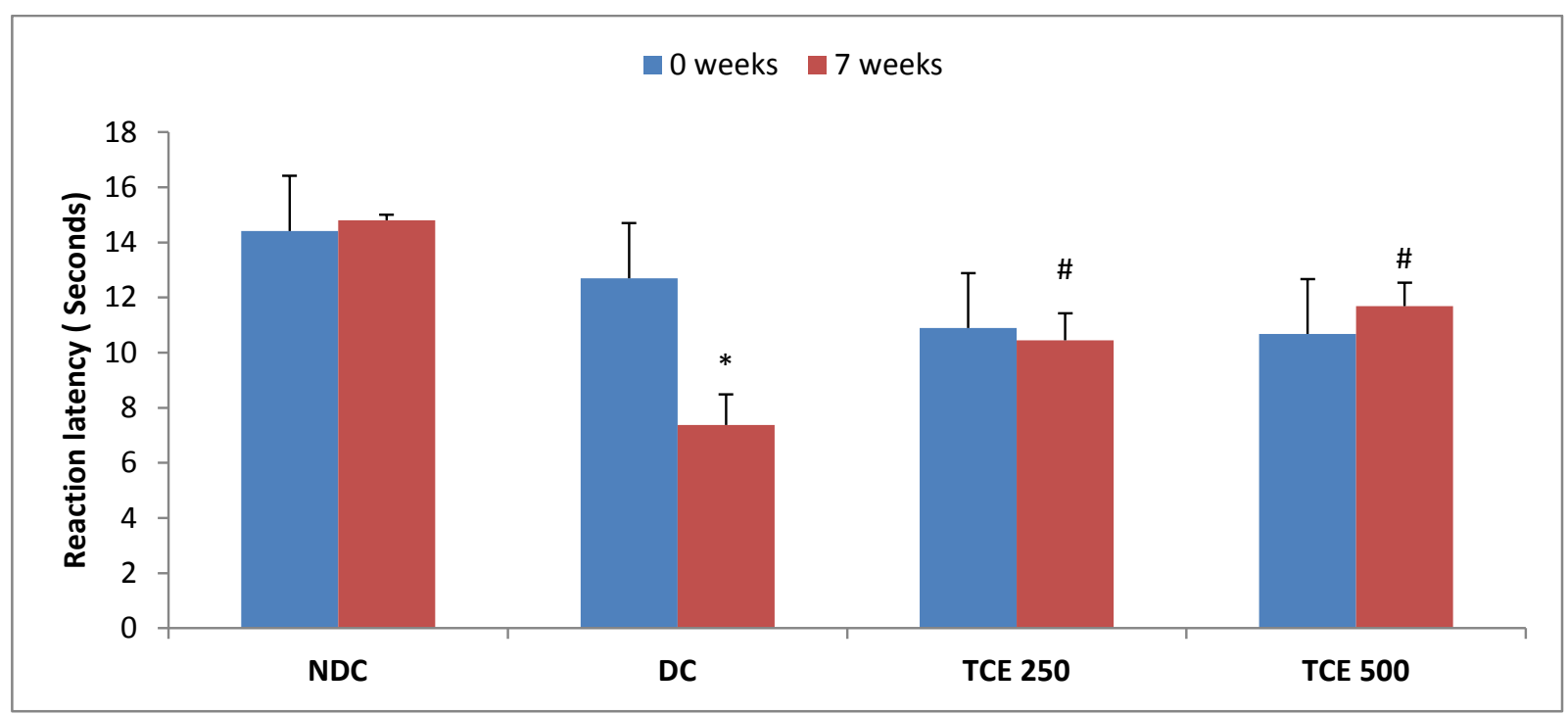

Values were expressed in Mean \pm SEM ( $n=8$ /group). ${ }^{*}$ Significantly different from Non diabetic control group $(\mathrm{p}<$ $0.05)$. " Significantly different from Diabetic control group $(\mathrm{p}<0.05)$.

NDC: Non diabetic Control TCE 250: Group treated with $250 \mathrm{mg}$ Tinospora cordifolia Extract

DC: Diabetic control TCE500: Group treated with 500 mg Tinospora cordifolia Extract

FIGURE 1 - Reaction latency on hot plate before and after treatment period.

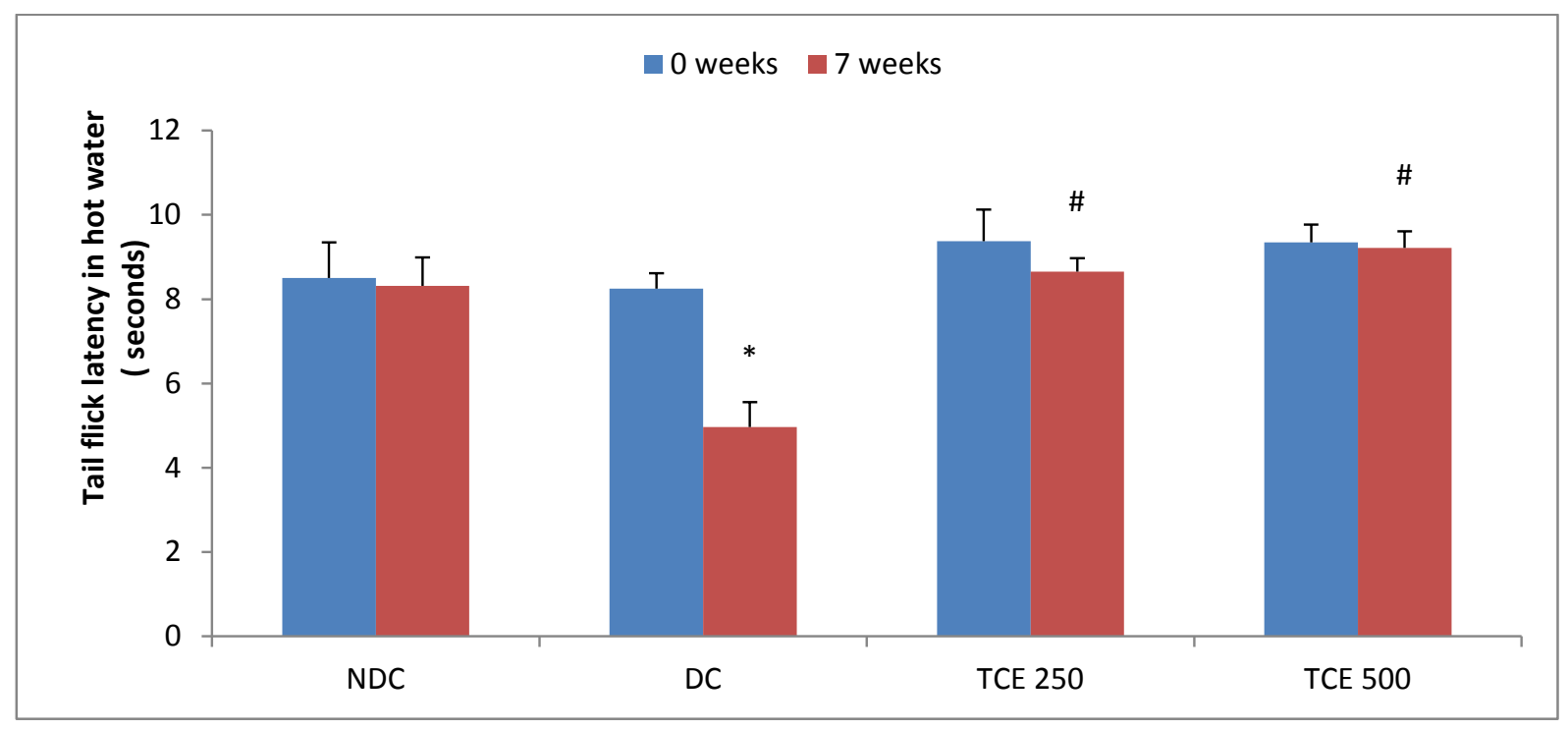

Values were expressed in Mean \pm SEM ( $\mathrm{n}=8$ /group). ${ }^{*}$ Significantly different from Non diabetic control group $(\mathrm{p}<$ $0.05) .{ }^{\#}$ Significantly different from Diabetic control group $(\mathrm{p}<0.05)$.

NDC: Non diabetic Control

DC: Diabetic control
TCE 250: Group treated with $250 \mathrm{mg}$ Tinospora cordifolia Extract TCE500: Group treated with $500 \mathrm{mg}$ Tinospora cordifolia Extract

FIGURE 2 - Tail flick latency in hot water before and after treatment period. 


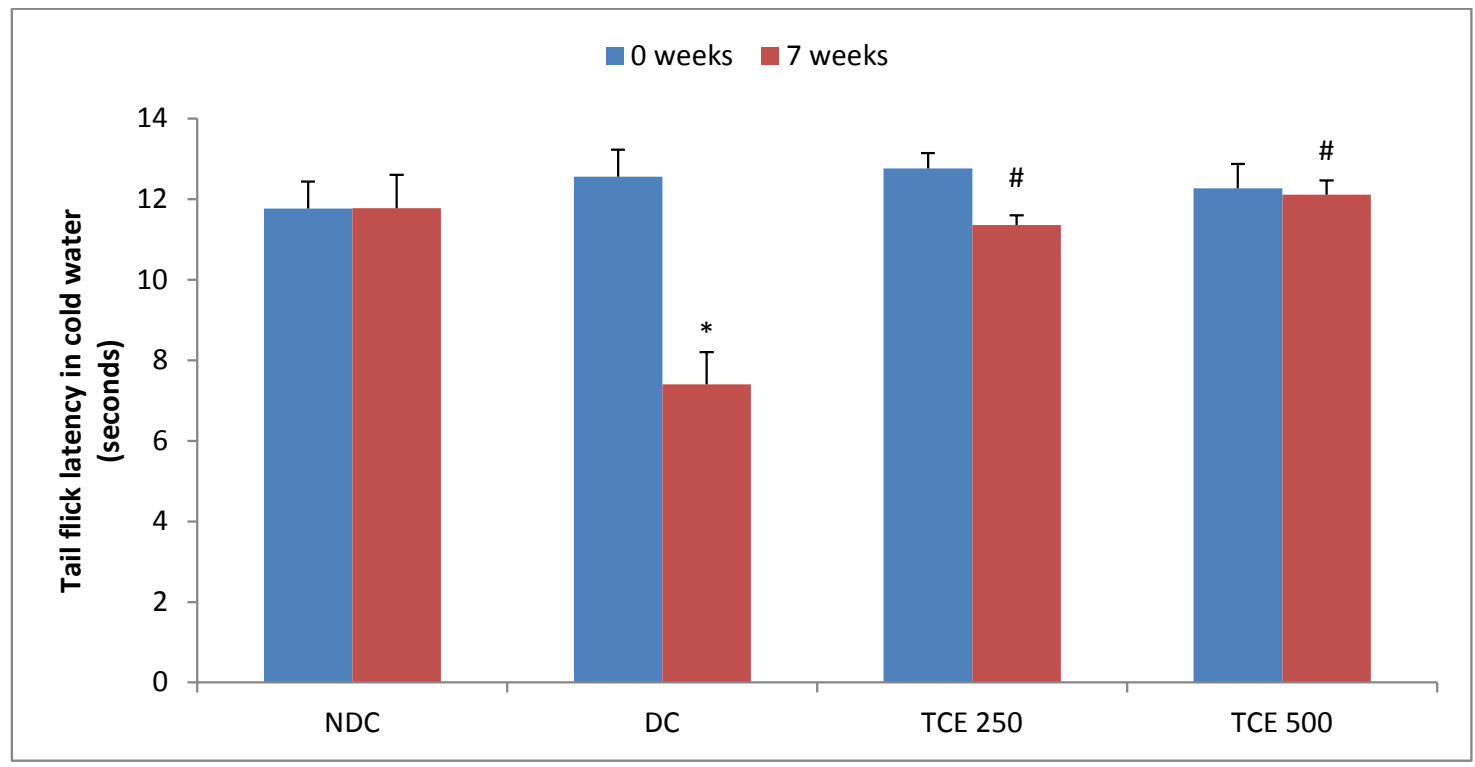

Values were expressed in Mean \pm SEM ( $n=8$ /group). ${ }^{*}$ Significantly different from Non diabetic control group $(p<$ 0.05). ${ }^{\#}$ Significantly different from Diabetic control group $(\mathrm{p}<0.05)$.

NDC: Non diabetic Control TCE 250: Group treated with $250 \mathrm{mg}$ Tinospora cordifolia Extract

DC: Diabetic control

TCE500: Group treated with $500 \mathrm{mg}$ Tinospora cordifolia Extract

FIGURE 3 - Tail flick latency in cold water before and after treatment period.

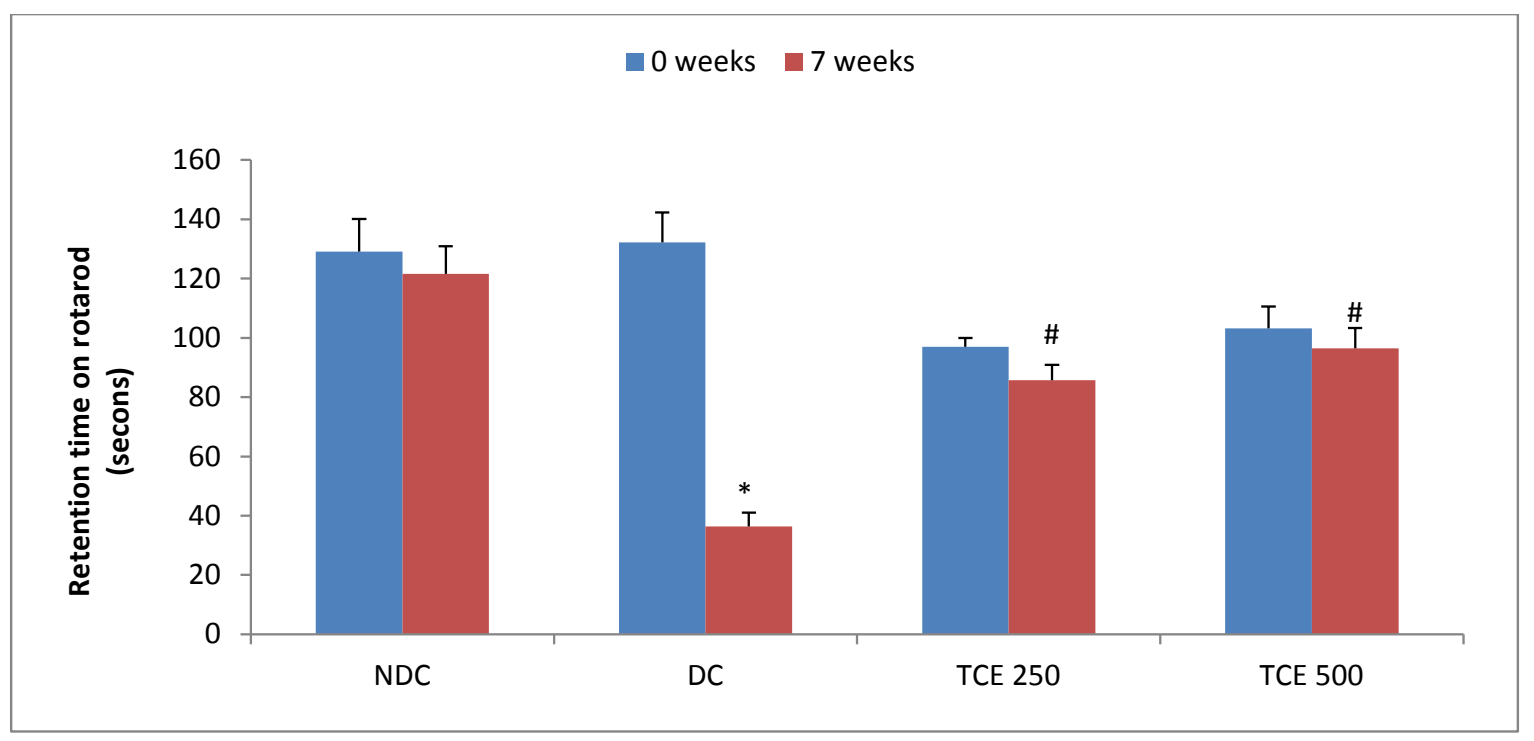

Values were expressed in Mean \pm SEM ( $n=8$ /group). ${ }^{*}$ Significantly different from Non diabetic control group $(p<$ 0.05). ${ }^{\text {A }}$ Significantly different from Diabetic control group $(\mathrm{p}<0.05)$.

NDC: Non diabetic Control

DC: Diabetic control
TCE 250: Group treated with $250 \mathrm{mg}$ Tinospora cordifolia Extract

TCE500: Group treated with 500 mg Tinospora cordifolia Extract

FIGURE 4 - Retention time on rotarod before and after treatment period. 


\section{The effect of TCE on sciatic nerve oxidative stress}

Significant reduction in antioxidant enzymes in the sciatic nerves of diabetic rats was observed after eight weeks of diabetes. Treatment with TCE 250 and TCE 500 restored the GSH levels in Diabetic animals. Catalase levels in the sciatic nerves of DN rats were significantly (51.53\%) less compared to NDC animals. TCE 500 treatment restored the Catalase levels to
$88.64 \%$ of Control levels. There was a $62.5 \%$ reduction in SOD levels in diabetic group and treatment with TCE 250 and TCE 500 restored the SOD levels to near normal to normal levels. There was a significant rise in MDA levels in sciatic nerves indicating the increased lipid peroxidation in the sciatic nerves of diabetic rats. Tinospora cordifolia significantly decrease the levels of MDA in diabetic rats' sciatic nerves in a dose dependent manner (Table II).

TABLE II - Effect of Tinospora cordifolia Extract (TCE) on sciatic nerve oxidative stress markers

\begin{tabular}{ccccc}
\hline Groups & $\begin{array}{c}\text { GSH } \\
\text { (nmole/mg protein) }\end{array}$ & $\begin{array}{c}\text { CAT } \\
\text { (units/mg protein) }\end{array}$ & $\begin{array}{c}\text { SOD } \\
\text { (units/mg protein) }\end{array}$ & $\begin{array}{c}\text { MDA } \\
\text { (n moles /mg protein) }\end{array}$ \\
\hline NDC & $3.55 \pm 0.16$ & $2.29 \pm 0.28$ & $2.64 \pm 0.21$ & $1.28 \pm 0.17$ \\
DC & $1.78 \pm 0.15^{*}$ & $1.11 \pm 0.10^{*}$ & $0.99 \pm 0.17^{*}$ & $3.78 \pm 0.24^{*}$ \\
TCE 250 & $3.31 \pm 0.21^{\#}$ & $1.24 \pm 0.08$ & $2.50 \pm 0.14^{\#}$ & $2.59 \pm 0.18^{\#}$ \\
TCE 500 & $3.45 \pm 0.41^{\#}$ & $2.03 \pm 0.18^{\#}$ & $2.72 \pm 0.13^{\#}$ & $2.47 \pm 0.19^{\#}$ \\
\hline
\end{tabular}

Values were expressed in Mean \pm SEM ( $\mathrm{n}=8 /$ group). ${ }^{*}$ Significantly different from Non diabetic Control $(\mathrm{p}<0.05)$. Significantly different from Diabetic control group $(\mathrm{p}<0.05)$.

NDC: Non diabetic Control

TCE 250: Group treated with $250 \mathrm{mg}$ Tinospora cordifolia Extract

DC: Diabetic control

TCE500: Group treated with $500 \mathrm{mg}$ Tinospora cordifolia Extract

\section{The effect of TCE on Diabetic neuropathy induced NGF expression in rat sciatic nerves}

NGF mRNA expression in sciatic nerves were detected by real time PCR. The data analysis revealed that there was a mean fold decrease in mRNA levels of
NGF (0.814 of control) in DC animals as compared to NDC animals. Treatment with TCE 250 and TCE 500 was able to bring significant elevation (1.969 and 3.483 times respectively) in mean fold change in mRNA levels of NGF compared to the control rats (Figure 5). Results were analyzed using Unpaired Student's t test. 


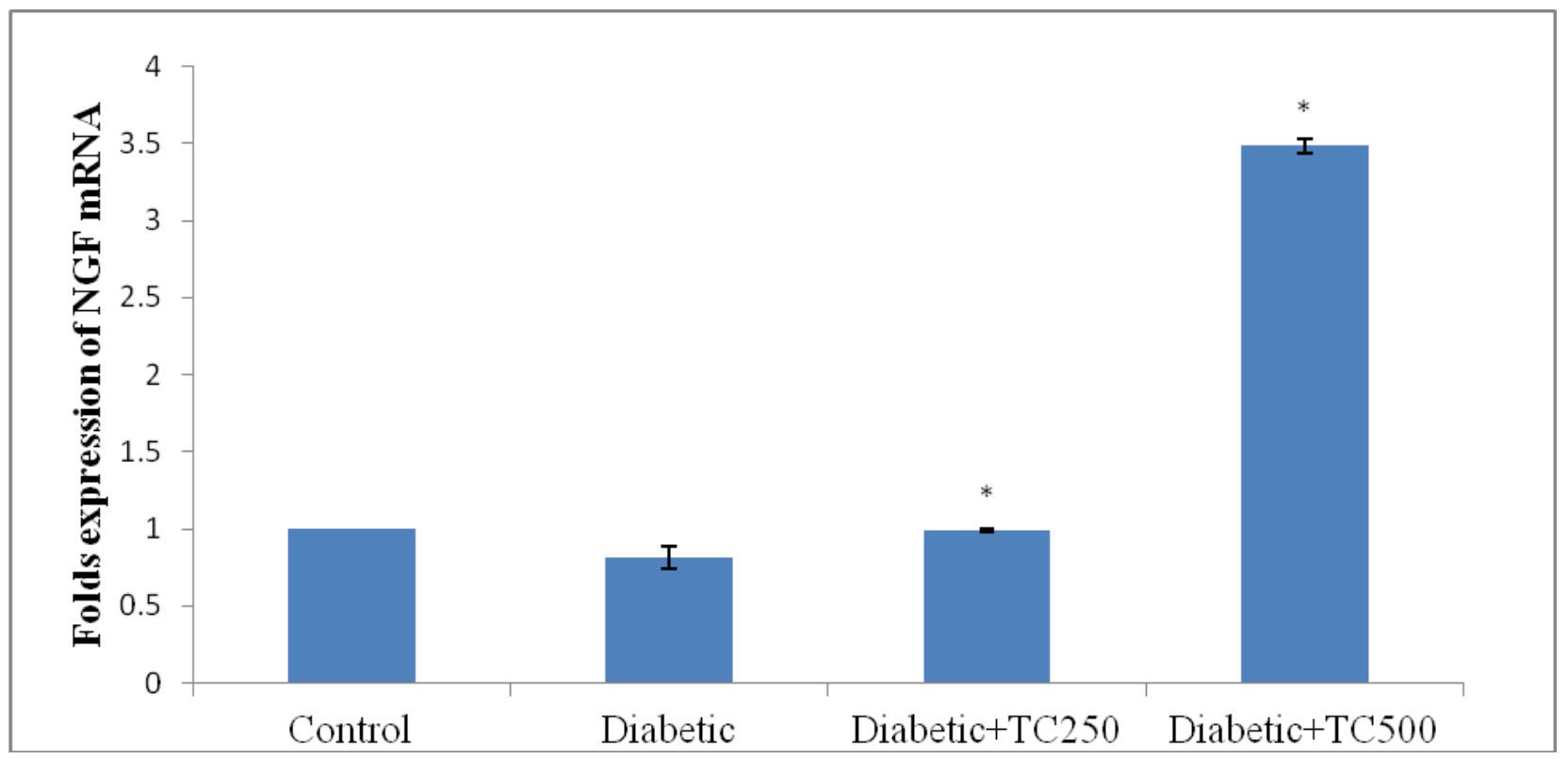

\section{Reaction (PCR).Data are mean \pm SEM. $(\mathrm{n}=5), * \mathrm{P}<0.05$ compare to control group \\ NDC: Non diabetic Control \\ DC: Diabetic control \\ TCE 250: Group treated with $250 \mathrm{mg}$ Tinospora cordifolia Extract \\ TCE500: Group treated with $500 \mathrm{mg}$ Tinospora cordifolia Extract}

FIGURE 5 - NGF m RNA Expression in Sciatic Nerve by Using Real-Time polymerase Chain.

\section{DISCUSSION}

The unified hypothesis considers that the oxidative stress launched by mitochondria is a common basic pathogenesis of diabetes and its chronic complications. Significant changes in oxidative status in animal models of diabetes has been clearly demonstrated (Cunha et al., 2008). Diabetic neuropathies accompanying Type 1 diabetes tend to occur more predictably and to progress more rapidly, resulting in a more severe neuropathy (Sugimoto et al., 2006). In hyperglycemic conditions, the absence of insulin-regulation in neurons makes these cells more prone to hyperglycemic insult (Thorburn et al., 1990). There is a positive correlation between both neuropathy severity and poor glycemic control with both the risk and intensity of neuropathic pain (Themistocleous et al., 2016)

Dyslipidemia may operate, separately or in combination with hyperglycemia to produce Neuropathy (Tesfaye, Selvarajah, 2009). The reduction of serum cholesterol and triglyceride following TCE treatment might facilitate better utilization of lipid along with reduction in hyperglycemia. TCE was able to correct the high triglyceride to normal, thereby indicating its possible action on lipase (Ravi et al., 2005).

In the present study the DC group showed thermal hyperalgesia (increased pain from a stimulus that usually provokes pain), allodynia (pain due to a stimulus that does not usually provoke pain) and sensimotor deficits, the characteristic symptoms of diabetic neuropathic pain by the end of 8 weeks of STZ injection. STZ-induced diabetic model exhibits hyperalgesia and allodynia that reflect neuropathic pain symptoms observed in diabetics (Gul et al., 2000; Kamei et al., 2001). A variety of pathophysiological mechanisms triggered by hyperglycemia leads to altered nociceptive responses (Courteix et al., 1993; Hounsom, Tomlinson, 1997). STZ induced Diabetes generate Reactive Oxygen Species (ROS) like Oxygen free radicals and leads to nerve damage (Low et al., 1991). The injured afferents causes the characteristic symptoms of neuropathic pain such as hyperalgesia and allodynia, (Shim et al., 2005). The Diabetic animals also exhibited muscle in-coordination besides hyperalgesia. 
The progressive loss of lower extremity sensation and, over time, motor weakness results in loss of balance, falls, and a numb, insensate foot (Pop-Busui et al., 2017). These sesimotor deficits can lead to significant impairment in Peripheral Diabetic Neuropathy (Shaikh, Somani, 2010). Here in this study, TCE prevented the development of neuropathic pain even in hyperglycemic conditions indicating the role of mechanisms other than antidiabetic action in the prevention DN.

Oxidative stress acts as a biochemical trigger for sciatic nerve damage and dysfunction (Figueroa-Romero et al., 2008). Long term hyperglycemia in diabetes disturbs the endogenous antioxidant defense mechanism by reducing the activity of reduced glutathione (GST) and $\mathrm{Cu}-\mathrm{Zn}$ superoxide dismutase (Yu et al., 2006; Cui et al., 2008). An increase in the lipid peroxidation products such as MDA $\mathrm{s}$ in sciatic nerves can be also seen in diabetes (Cunha et al., 2008).

Glutathione, a potent endogenous antioxidant is a first line of defense against free radicals. In the present study, GSH levels were significantly lowered in the sciatic nerve of diabetic animals. The decrease in GSH levels in sciatic nerves was reversed with TCE treatment in a dose dependent way. Tinospora Cordifolia exerts cell/neuroprotective properties via preventing the depletion and increasing GSH levels and it might be by inducing GCLC expression (Rawal et al., 2004).

Superoxide anion is one of the key mediators of glucose-induced oxidative injury. These highly reactive superoxide anions $\left(\mathrm{O}_{2}{ }^{\prime}\right)$ are converted to $\mathrm{H} 2 \mathrm{O} 2$ by Super oxide Dismutase (SOD) enzyme. A reduction in the activity of SOD can be seen in the sciatic nerve of diabetic animals and it might be due to non-enzymatic glycosylation (Tiwari et al., 2013).The decreased Catalase activity in diabetes might reduce protection against free radicals. The simultaneous reduction in the activity of both SOD and CAT in diabetic condition makes the sciatic nerve more vulnerable to hyperglycemia induced oxidative stress (Demir, Inal-Erden, 1998). Both the doses of TCE significantly restored the SOD levels in diabetic rats. High dose of TCE appreciably restored the Catalase levels in the sciatic nerves of diabetic rats. The results we obtained revealed that TCE has protected the sciatic nerve from oxidative stress induced damage by restoring the activity SOD and CAT. The lipid peroxidation in diabetic sciatic nerve results into a variety of chain reactions which finally lead to cell damage (Gutteridge, 1995).

In the present experiment Tinospora cordifolia extracts increased the antioxidant enzyme level and reduced the lipid peroxidation in the sciatic nerves. The presence of phenols, flavonoids, and tannins in TCE attributes the free radical scavenging activity (Priti, 2017). Tinospora cordifolia has an alpha-glucosidase inhibitor, characterized as saponarin was found to have significant antioxidant activity. Arabinogalactan, a polysachharide present Tinospora cordifolia shows protection against free radicals in rat model indicating its antioxidant action (Subramanian et al., 2002). The earlier works reported that alkaloids of Tinospora cordifolia inhibits lipid peroxidation and increases the antioxidant status in animals intoxicated with xenobiotic compounds (Singh et al., 2006). Hence the anti nociceptive potential found in present research might be due to antioxidant potential of saponarin and other anti oxidant principles of the Tinospora cordifolia extract.

Gene expression changes in fibroblasts, endothelial cells, and sciatic nerve-associated adipocytes were consistent with structural changes of axonal degeneration in sciatic nerves in diabetic animals (Pande et al., 2011). NGF was the first discovered and a most important neurotrophic factor. It plays a crucial role in neuronal development and differentiation. NGF is responsible for nerve regeneration. Besides, it protects neurons and reduces their degeneration and death. NGF is deficient in diabetics and reduced levels or activity of NGF can play a significant role in the pathogenesis of DN (Zhang et al., 2007). Here in this study TCE induced the expression of NGF $m$ RNA in diabetic rat sciatic nerve which is responsible for preventing axonal damage in diabetic sciatic nerves. Phytosterols like b-sitosterol are reported to have neuroprotective action (Ayaz et al., 2017) The neuroprotective effect of TCE can be attributed to the sterols, b-sitosterol, d-sitosterol, gsitosterol, b-hydroxygenase, ecdysterone, makisterone, giloinsteroljateorine, columbin present in it.

\section{CONCLUSION}

Although Diabetic Neuropathy can be triggered by hyperglycemic conditions, the final toxicity to the nerves is contributed by multiple complex pathways. In many of these pathways oxidative stress is the unifying mechanism. Amelioration of this oxidative stress could halt the progress of Diabetic Neuropathy and its symptoms even in long-term diabetes where strict glycemic control is very difficult to keep up. In the present study seven weeks treatment with Tinospora cordifolia reversed the thermal 
hyperalgesia, allodynia, motor deficits and pathological changes of sciatic nerves. Hence Tinospora cordifolia might be a potential supplement in preventing early diabetic neuropathic symptoms. Isolation, characterization of active ingredient(s) responsible for the neuroprotective effect of Tinospora cordifolia and evaluation of functional biomarkers like sensory nerve conduction velocity and motor nerve conduction velocity measurements in upcoming research can prove the potential of this herb in the prevention and treatment of Diabetic neuropathy.

\section{REFERENCES}

Aebi H. Catalase in vitro. In Methods in enzymology. Academic Press; 1984. p. 121-126.

Ayaz M, Junaid M, Ullah F, Subhan F, Sadiq A, Ali G, et al. Anti-Alzheimer's studies on $\beta$-sitosterol isolated from Polygonum hydropiper L. Front Pharmacol. 2017;8:697.

Courteix C, Eschalier A, Lavarenne J. Streptozocin-induced diabetic rats: behavioural evidence for a model of chronic pain. Pain. 1993;53(1):81-8.

Cui XP, Li BY, Gao HQ, Wei N, Wang WL, Lu M. Effects of grape seed proanthocyanidin extracts on peripheral nerves in streptozocin-induced diabetic rats. J Nutr Sci Vitaminol. 2008;54(4):321-8.

Cunha JM, Jolivalt CG, Ramos KM, Gregory JA, Calcutt NA, Mizisin AP. Elevated lipid peroxidation and DNA oxidation in nerve from diabetic rats: effects of aldose reductase inhibition, insulin, and neurotrophic factors. Metab Clin Exp. 2008;57(7):873-81.

Demir S, Inal-Erden M. Pentoxifylline and N-acetylcysteine in hepatic ischemia/reperfusion injury. Clin Chim Acta. 1998;275(2):127-35.

Ellman GL. Tissue sulfhydryl groups. Arch Biochem Biophys. 1959;82(1):70-7.

Figueroa-Romero C, Sadidi M, Feldman EL. Mechanisms of disease: the oxidative stress theory of diabetic neuropathy. Rev Endocr Metab Disord. 2008;9(4):301-14.

Gul H, Yildiz O, Dogrul A, Yesilyurt O, Isimer A. The interaction between IL-1 $\beta$ and morphine: possible mechanism of the deficiency of morphine-induced analgesia in diabetic mice. Pain. 2000;89(1):39-45.

Gutteridge JM. Lipid peroxidation and antioxidants as biomarkers of tissue damage. Clin Chem. 1995;41(12):1819-28.
Hosseini A, Abdollahi M. Diabetic Neuropathy and Oxidative Stress: Therapeutic Perspectives. Oxid Med Cell Longevity. 2013;2013:168039.

Hounsom L, Tomlinson DR. Does neuropathy develop in animal models? Clin Neurosci. 1997; 4(6):380-9.

International Diabetes Federation. IDF Diabetes Atlas, 8th edn. Brussels, Belgium: International Diabetes Federation, 2017.

Jakobsen LK. Quantitative determination of blood glucose using glucose oxidase and peroxidase. Scand J Clin Lab Invest. 1960;12(1):76-79.

Kakkar P, Das B, Viswanathan PN. A modified spectrophotometric assay of superoxide dismutase. 1984.

Kamboj SS, Vasishta RK, Sandhir R. N-acetylcysteine inhibits hyperglycemia-induced oxidative stress and apoptosis markers in diabetic neuropathy. J Neurochem. 2010;112(1):77-91.

Kamei J, Mizoguchi H, Narita M, Tseng LF. Therapeutic potential of PKC inhibitors in painful diabetic neuropathy. Expert Opin Invest Drugs. 2001;10(9):1653-64.

Low PA, Nickander KK. Oxygen free radical effects in sciatic nerve in experimental diabetes. Diabetes. 1991;40(7):873-7.

Morani AS, Bodhankar SL. Neuroprotective effect of early treatment with pioglitazone and pyridoxine hydrochloride in alloxan induced diabetes in rats. Pharmacol online. 2007;2:418-28.

Ohkawa H, Ohishi N, Yagi K. Assay for lipid peroxides in animal tissues by thiobarbituric acid reaction. Anal Biochem. 1979;95(2):351-8.

Osikowicz M, Mika J, Makuch W, Przewlocka B. Glutamate receptor ligands attenuate allodynia and hyperalgesia and potentiate morphine effects in a mouse model of neuropathic pain. Pain. 2008;139(1):117-26.

Øvstebø R, Haug KB, Lande K, Kierulf P. PCR-based calibration curves for studies of quantitative gene expression in human monocytes: development and evaluation. Clinical Chemistry. 2003;49(3):425-32.

Pabreja K, Dua K, Sharma S, Padi SS, Kulkarni SK. Minocycline attenuates the development of diabetic neuropathic pain: possible anti-inflammatory and antioxidant mechanisms. Eur J Pharmacol. 2011; 661(1-3):15-21.

Pande M, Hur J, Hong Y, Backus C, Hayes JM, Oh SS, et al. Transcriptional profiling of diabetic neuropathy in the BKS 
$\mathrm{db} / \mathrm{db}$ mouse: a model of type 2 diabetes. Diabetes. 2011: DB_101541.

Pandey PK, Pandey M, Sharma R. Defluoridation of water by a biomass: Tinospora cordifolia. J Environ Prot. 2012;3(07):610.

Pop-Busui R, Boulton AJ, Feldman EL, Bril V, Freeman R, Malik RA, et al. Diabetic neuropathy: a position statement by the American Diabetes Association. Diabetes care. 2017;40(1):136-54.

Praveen N, Thiruvengadam M, Kim HJ, Praveen Kumar JK, Chung IM. Antioxidant activity of Tinospora cordifolia leaf extracts through non-enzymatic method. J Med Plants Res. 2012;6(33):4790-4795.

Priti SR. Phytochemical screening, antibacterial and antioxidant activity of leaves extract of Tinospora cordifolia. J Pharm Res. 2017;11(8):991.

Ravi K, Rajasekaran S, Subramanian S. Antihyperlipidemic effect of Eugenia jambolana seed kernel on streptozotocininduced diabetes in rats. Food Chem Toxicol. 2005;43(9):1433-9.

Rawal AK, Muddeshwar MG, Biswas SK. Rubia cordifolia, Fagonia cretica linn and Tinospora cordifolia exert neuroprotection by modulating the antioxidant system in rat hippocampal slices subjected to oxygen glucose deprivation. BMC Complementary Altern Med. 2004;4(1):11.

Sengupta S, Mukherjee A, Goswami R, Basu S. Hypoglycemic activity of the antioxidant saponarin, characterized as alphaglucosidase inhibitor present in Tinospora cordifolia. J Enzyme Inhib Med Chem. 2009;24:684-90.

Shaikh AS, Somani RS. Animal models and biomarkers of neuropathy in diabetic rodents. Indian $\mathrm{J}$ Pharmacol. 2010;42(3):129.

Shim B, Kim DW, Kim BH, Nam TS, Leem JW, Chung JM. Mechanical and heat sensitization of cutaneous nociceptors in rats with experimental peripheral neuropathy. Neuroscience. 2005;132(1):193-201.

Singh RP, Banerjee S, Kumar PV, Raveesha KA, Rao AR. Tinospora cordifolia induces enzymes of carcinogen/ drug metabolism and antioxidant system, and inhibits lipid peroxidation in mice. Phytomedicine. 2006;13:74-8.

Subramanian M, Chintalwar GJ, Chattopadhyay S. Antioxidant properties of a Tinospora cordifolia polysaccharide against iron-mediated lipid damage and $\gamma$-ray induced protein damage. Redox Rep. 2002;7(3):137-43.

Sugimoto K, Murakawa Y, Sima AA. Diabetic neuropathy-a continuing enigma. Diabetes/Metab Res Rev. 2000 ;16(6): 408-33.
Szolcsányi J, Bölcskei K, Szabó Á, Pintér E, Pethő G, Elekes K, et al. Analgesic effect of TT-232, a heptapeptide somatostatin analogue, in acute pain models of the rat and the mouse and in streptozotocin-induced diabetic mechanical allodynia. Eur J Pharmacol. 2004;498(1-3):103-9.

Tesfaye S, Selvarajah D. The Eurodiab study: what has this taught us about diabetic peripheral neuropathy? Curr Diabetes Rep. 2009;9(6):432.

Thatte U, Bagadey S, Dahanukar S. Modulation of programmed cell death by medicinal plants. Cell Mol Biol. 2000;46(1):199-214.

Themistocleous AC, Ramirez JD, Shillo PR, Lees JG, Selvarajah D, Orengo C, et al. The Pain in Neuropathy Study (PiNS): a cross-sectional observational study determining the somatosensory phenotype of painful and painless diabetic neuropathy. Pain. 2016;157(5):1132.

Thorburn AW, Gumbiner B, Brechtel G, Henry RR. Effect of hyperinsulinemia and hyperglycemia on intracellular glucose and fat metabolism in healthy subjects. Diabetes. 1990;39(1):22-30.

Tiwari BK, Pandey KB, Abidi AB, Rizvi SI. Markers of oxidative stress during diabetes mellitus. J Biomarkers. 2013;2013:378790.

Yu J, Zhang Y, Sun S, Shen J, Qiu J, Yin X, et al. Inhibitory effects of astragaloside IV on diabetic peripheral neuropathy in rats. Can J Physiol Pharmacol. 2006;84(6):579-87.

Zhang W, Kamiya H, Ekberg K, Wahren J, Sima AA. Cpeptide improves neuropathy in type 1 diabetic BB/Wor-rats. Diabetes Metab Res Rev. 2007;23:63-70.

Received for publication on $25^{\text {th }}$ June 2018 Accepted for publication on $21^{\text {st }}$ January 2019 